\title{
Observations on the Maturation of Thyroid
}

\author{
Function in Early Fetal Life
}

\author{
Arnold H. Greenberg, Paul Czernichow, Richard C. Reba, \\ John Tyson, and Robert M. BLIzZARD \\ From the Departments of Pediatrics, Medicine, and Obstetrics, The Johns \\ Hopkins University School of Medicine, Baltimore, Maryland 21205
}

A B S T R A C T Serum samples were obtained from 21 normal human fetuses after therapeutic abortion for psychiatric indications. Fetal crown-rump length ranged from 5.2 to $22.5 \mathrm{~cm}$, corresponding to the gestational age of $65-168$ days.

Serum thyroxine, assayed by a modification of the Murphy-Pattee method, was identified in the second * smallest fetus examined at 78 days gestation. Thereafter it increased rapidly, maintaining a significant linear correlation with crown-rump length until term $(r=0.800$, $P<0.001$ ). Free thyroxine (FT4) also increased in a linear relation to gestational age $(r=0.908, P<0.001)$, but reached term levels by 18-20 wk. Radioimmunoassayable thyroid-stimulating hormone (TSH) was detected at 78 days gestation. Levels increased rapidly with advancing gestation, so that by $16 \mathrm{wk}$ almost all were within the range of term infants. After $16 \mathrm{wk}$ gestation, levels were usually greater than $4.0 \mu \mathrm{U} / \mathrm{cc}$, higher than that seen in normal children.

No correlation was demonstrated between the serum TSH levels and total thyroxine. TSH and FT4, however, increased in a parallel manner with a significant positive correlation. This suggested that fetal TSH secretion was responsive to FT4 levels from very early in gestation, possibly as early as $11 \mathrm{wk}$.

Thyroxine-binding globulin (TBG) was detected in a fetus of 78 days gestation $(1.4 \mu \mathrm{g} / 100 \mathrm{ml})$. Levels increased rapidly, paralleling the rise in serum thyroxine and maintaining a linear correlation with crownrump length $(r=0.864, P<0.001)$. Thyroxine-binding prealbumin binding capacity (TBPA) in fetuses 14-24 wk gestation was comparable with that seen at term.

When examining the distribution of tracer amounts of thyroxine $-{ }^{131} \mathrm{I}\left(\mathrm{T} 4-{ }^{131} \mathrm{I}\right)$ between the thyroxine-binding

This work was presented at the 1969 Annual Meeting of The American Thyroid Association, Chicago, Ill.

Received for publication 2 January 1970 and in revised form 14 April 1970. proteins, it was found that a major fraction was bound to TBPA and albumin during the early part of gestation. This decreased linearly with maturation of the fetus as the fraction bound to TBG increased. By $20 \mathrm{wk}$ gestation fetal TBG was able to bind $78 \%$ of tracer despite a TBG capacity of only $7.7 \mu \mathrm{g} / 100 \mathrm{ml}$. This appeared to be the result of relatively low concentrations of TBPA and albumin during this period of gestation. The theoretical association constant calculated for fetal and newborn TBG was found to be similar to that estimated for normal adult males and females.

\section{INTRODUCTION}

The functional and anatomical development of the fetal thyroid and pituitary glands has been partially characterized in earlier studies. Shepard has described the morphologic differentiation of the human fetal thyroid (1) and the onset of iodothyronine and iodotyrosine production (2). Studies of fetal pituitary embryogenesis by Pearse (3) and Rosen and Ezrin (4) delineated the cytologic differentiation of the pituitary basophil and thyrotroph cells; and recently Gitlin and Biasucci (5) described the ontogenesis of thyroid-stimulating hormone production in fetal pituitary tissue cultures.

The present study was undertaken to correlate the appearance of thyroid-stimulating hormone (TSH) and thyroxine in the circulation of the human fetus and to examine the relation of each to the other and to the thyroxine-binding proteins during fetal development. In addition, we have investigated these parameters in paired maternal and fetal sera in an attempt to define the relation of material and fetal thyroid function.

\section{METHODS}

Subjects. 21 grossly normal human fetuses were obtained immediately after therapeutic abortion. Blood was drawn by cardiac puncture and/or cord exsanguination. Seven maternal sera were obtained before anesthesia was admin- 
istered for the hysterotomy. All pregnancies were uncomplicated, and all abortions were done for psychiatric indications only. Paired maternal and cord sera from normal full-term newborns were also examined.

Methods. Serum thyroxine was determined by the modified method of Murphy and Jachan (6) using the Tetrasorb Kit (Abbott Laboratories Ltd., Queenborough, Kent, Eng.). Results are expressed as $\mu \mathrm{g} / 100 \mathrm{ml}$ of thyroxine corrected for the recovery of the extraction.

Thyroxine-binding globulin binding capacity (TBG) was assessed using reverse-flow paper electrophoresis in glycine acetate buffer, $\mathrm{pH} 8.6$ (7). Each serum was enriched with $5.7 \mu \mathrm{g} / 100 \mathrm{ml}$ of thyroxine- ${ }^{181} \mathrm{I}\left(\mathrm{T} 4{ }^{-181} \mathrm{I}\right)$. Sera from older fetuses were assayed with 50 and $100 \mu \mathrm{g} / 100 \mathrm{ml}$ of added L-thyroxine to determine maximal binding capacity, and sera from younger fetuses with 25 and $50 \mu \mathrm{g} / 100 \mathrm{ml}$. Maximal binding capacity of maternal sera was assessed with 300 and $400 \mu \mathrm{g} / 100 \mathrm{ml}$ of added L-thyroxine, and fullterm infants with 200 and $300 \mu \mathrm{g} / 100 \mathrm{ml}$. Thyroxine-binding prealbumin binding capacity (TBPA) was assessed with 800 and $1000 \mu \mathrm{g} / 100 \mathrm{ml}$ of added L-thyroxine in all specimens. The relative distribution of $\mathrm{T} 4{ }^{-131} \mathrm{I}$ between the fetal thy roxine-binding proteins was determined after the addition of $1.5 \mu \mathrm{g} / 100 \mathrm{ml}$ of T4- ${ }^{181} \mathrm{I}$. A current of $12.0 \mathrm{ma}$ was applied for $18 \mathrm{hr}$ and the electrophoresis strips were dried and then scanned for radioactivity in an automatic gas flow

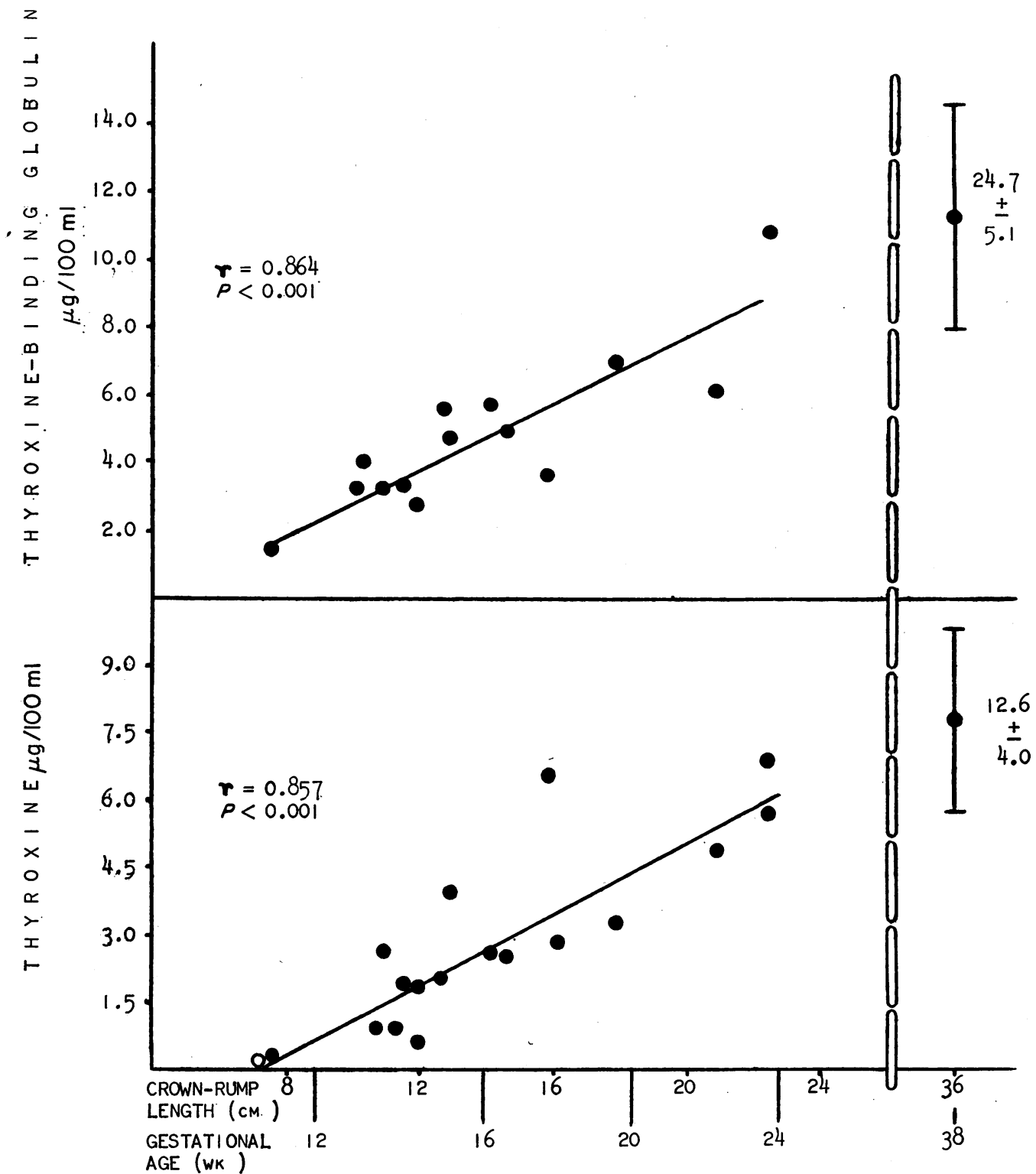

FIGURE $1 \mathrm{~A}$ Fetal thyroxine and thyroxine-binding globulin (TBG) concentration compared with term levels during the gestational period from 11 to $24 \mathrm{wk}$. A highly significant linear correlation is maintained during this period of fetal development. 


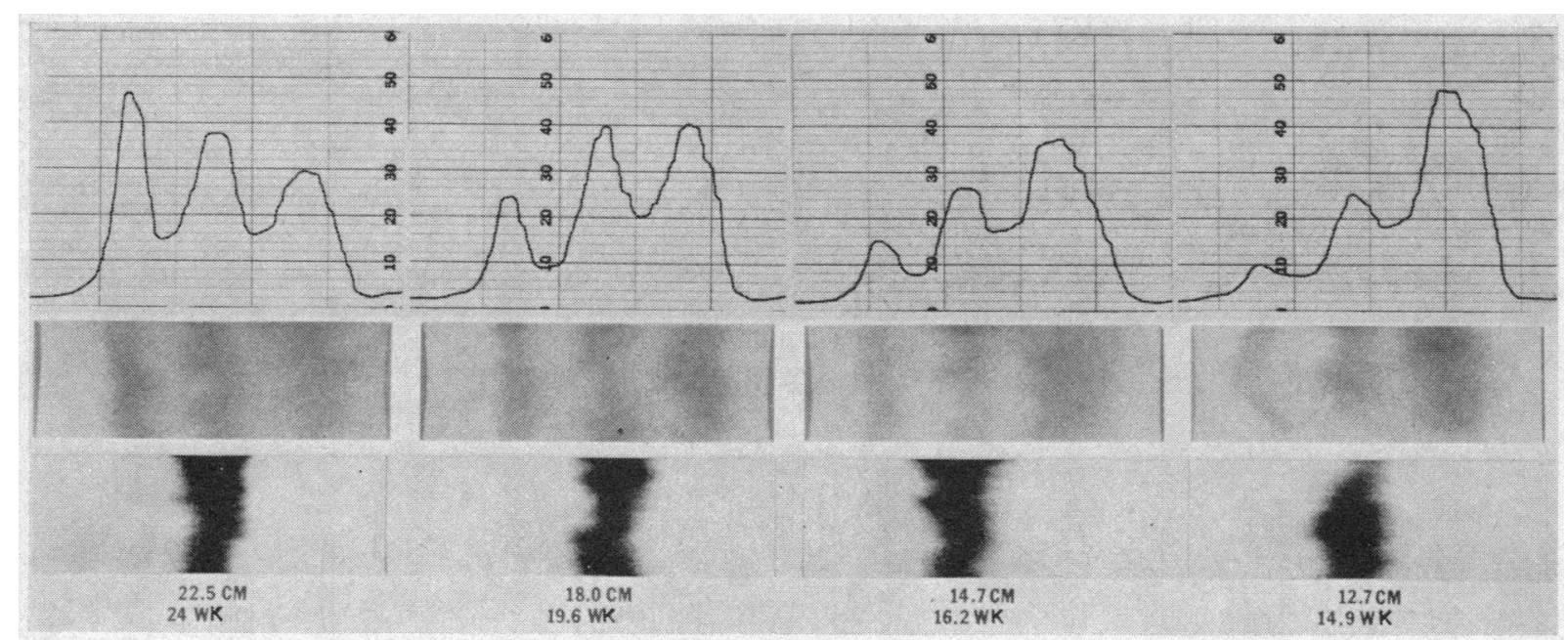

Figure $1 \mathrm{~B}$ Thyroxine- ${ }^{131} \mathrm{I}$ distribution in four fetal sera of decreasing gestational age. All sera contain $50 \mu \mathrm{g} / 100 \mathrm{ml}$ of $\mathrm{L}$-thyroxine and $5.7 \mu \mathrm{g} / 100 \mathrm{ml}$ of thyroxine- ${ }^{181} \mathrm{I}$. The upper row represents the tracings of the automatic gas flow counterscan, and the middle row represents the radioautographs of the electrophoretic strips. In the lower row the same strips are stained with bromphenol blue to illustrate the position of the albumin. The anode is to the right. The 14.9 wk fetus, on the right, has little thyroxine- ${ }^{181} \mathrm{I}$ bound to the TBG, while most is bound to TBPA. TBG-bound thyroxine- ${ }^{131} \mathrm{I}$ then increases with advancing fetal maturity.

counter. The distribution of radioactivity was assessed by manual planimetry. The coefficient of variation for intraand inter-assay variability at $95 \%$ confidence limits was 11.2 and $16.7 \%$, respectively.

Free thyroxine was assayed by the method of Sterling and Brenner (8). Purity of the T4- ${ }^{131} \mathrm{I}$ (Abbott Laboratories Ltd.) was determined by thin-layer chromatography on cellulose plates using a two-dimensional system (9). Thyroxine accounted for $94.4 \%$ of the radioactivity, iodide for $3.9 \%$, and triiodothyronine for $1.7 \%$. The $\mathrm{T} 4{ }^{-181} \mathrm{I}$ was then dialyzed against 8 liters of $0.15 \mathrm{M}$ potassium phosphate buffer, $\mathrm{pH} \mathrm{7.4,} \mathrm{for} 48 \mathrm{hr}$ before use in the assay (10). All samples were assayed in duplicate in single assay at a dilution of $1: 25$. The free thyroxine fraction (FT4F) was corrected for the dilution, and the absolute free thyroxine concentration (FT4) was calculated as the product of the FT4F and serum thyroxine concentration. The coefficient of variation for intra-assay variability at $95 \%$ confidence limits was $5.7 \%$.

The TSH radioimmunoassay was previously described (11). All samples were measured in duplicate or triplicate in a single assay. When sufficient serum was available, samples were analyzed at two dilutions. The coefficient of variation for intra-assay variability assessed in the hypothyroid and normal range of the standard curve was 14.1 and $4.1 \%$ respectively.

Fetal serum proteins were separated by using the Beckman microzone electrophoresis system (Beckman Instruments, Fullerton, Calif.) on a cellulose acetate membrane in barbital buffer, $\mathrm{pH} 8.6$, ionic strength 0.075 . The membrane was scanned with an Analytrol densitometer (Spinco Div., Beckman Instruments),

\section{RESULTS}

The relationship of serum thyroxine concentration and TBG capacity for fetuses 11-24 wk gestation and for normal full-term infants (38 wk gestation) is illustrated in Fig. 1. The crown-rump length is plotted with the corresponding gestational age as predicted by Streeter (12). The serum of the second smallest fetus (78 days gestation) contained thyroxine. None was detectable in a fetus of 74 days gestation; however, sufficient serum was not available for extraction of more than a $500 \mu 1$ sample. The serum thyroxine levels increased linearly from 78 days to 24 wk gestation. These values correlated significantly with the crown-rump length $(r=$ $0.857, P<0.001)$. Thyroxine-binding globulin $(1.4 \mu \mathrm{g} /$ $100 \mathrm{ml}$ ) was present in the serum of the youngest fetus assayed (78 days). Fetal TBG increased linearly when

TABLE I

Maximal Binding Capacity of Thyroxine-Binding Prealbumin $(T B P A)$ in Eight Fetal and Nine Newborn Sera

\begin{tabular}{ccc}
\hline $\begin{array}{c}\text { Crown-rump } \\
\text { length }\end{array}$ & $\begin{array}{c}\text { Estimated } \\
\text { gestational } \\
\text { age }\end{array}$ & TBPA \\
\hline$c m$ & $w k$ & $\mu g / 100 ~ m l$ \\
11.4 & 11.5 & 232 \\
14.7 & 16.5 & 123 \\
15.9 & 17.5 & 193 \\
17.0 & 18.6 & 212 \\
18.0 & 19.4 & 117 \\
21.0 & 22.0 & 114 \\
22.5 & 23.8 & 134 \\
22.5 & 23.8 & 106 \\
Full term & 38.0 & $150 \pm 30$ (Mean \pm SEM)
\end{tabular}




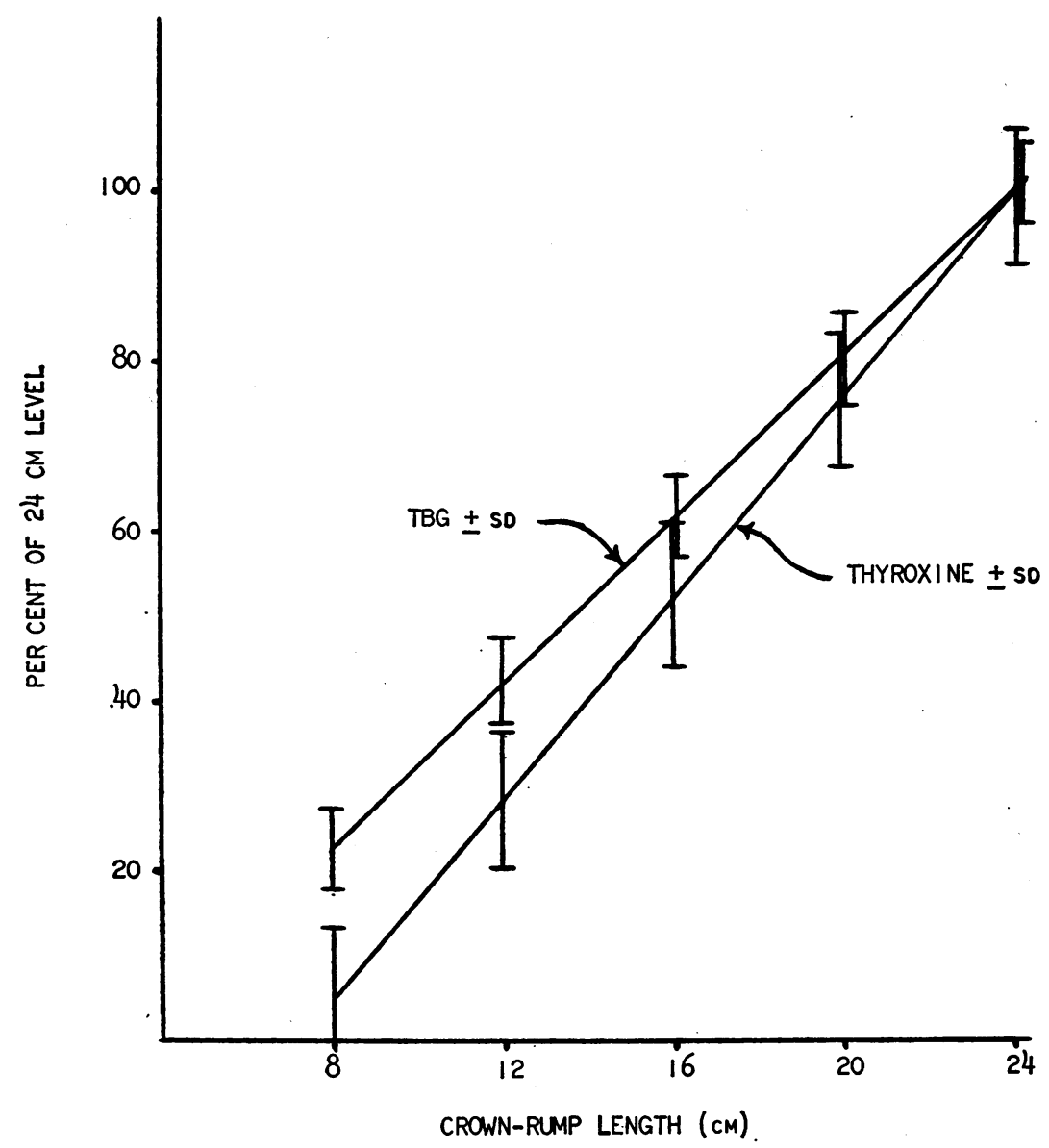

FIGURE 2 Comparison of the regression of thyroxine and TBG ( $\pm \mathrm{SD}$ ) vs. gestational age, expressed as a percentage of the respective 24-cm fetal levels. Although the analysis of linear covariance was not significantly different $(F=1.58, P>0.5)$, thyroxine levels do appear to reach their $24 \mathrm{~cm}$ level at a more rapid rate.

related to crown-rump length $(r=0.864, P<0.001)$ (Figs. 1A and 1B).

Expressing serum thyroxine and TBG concentration as a percentage of the $24-\mathrm{cm}$ fetal levels predicted by the respective regression lines, the relative rates of change of the two parameters can be estimated (Fig. 2). By the analysis of linear covariance, the rates of increase in TBG and thyroxine levels were not significantly different $(F=1.58, P>0.5)$. The interpretation of the statistical analysis, however, is limited by the large variation about the regression lines due primarily to the small sample size in both groups. It can be noted in Fig. 2 that the thyroxine levels do appear to be increasing at a slightly more rapid rate than TBG levels.

The maximal binding capacity of TBPA in eight fetal sera ranging from 11.5 to 23.8 wk estimated gestational age and in nine full-term newborns is given in Table I. All fetal specimens were within the newborn range. However, both fetal and newborn TBPA are significantly lower than that seen in children 5-12 yr of age $(299 \pm 38$ (SEM) $\mu \mathrm{g} / 100 \mathrm{ml}$.

\section{TABLE II}

Fetal Serum Proteins in Eight Specimens of Increasing Gestational Age

\begin{tabular}{ccccccc}
\hline $\begin{array}{c}\text { Crown- } \\
\text { rump } \\
\text { length }\end{array}$ & $\begin{array}{c}\text { Gesta- } \\
\text { tional } \\
\text { age }\end{array}$ & \multicolumn{2}{c}{ Fetoprotein } & Albumin & $\begin{array}{c}\text { Total } \\
\text { protein }\end{array}$ \\
\hline$c m$ & $w k$ & $\%$ & $g / 100$ & $\%$ & $g / 100$ & $g / 100$ \\
& & & $m l$ & & $m l$ & $m l$ \\
5.2 & 9.2 & 19.4 & 0.43 & 37.3 & 0.56 & 2.1 \\
11.0 & 13.6 & 10.4 & 0.23 & 73.4 & 1.62 & 2.2 \\
12.8 & 15.2 & 10.0 & 0.22 & 77.0 & 1.69 & 2.2 \\
14.7 & 16.6 & 5.2 & 0.16 & 72.9 & 2.23 & 3.1 \\
15.9 & 17.7 & 6.1 & 0.17 & 75.8 & 2.12 & 2.8 \\
18.0 & 19.4 & 3.3 & 0.08 & 82.2 & 2.07 & 2.4 \\
22.5 & 24.0 & 0 & 0 & 83.2 & 2.58 & 3.1 \\
36.0 & 38.0 & 0 & 0 & 66.9 & 3.82 & 5.7 \\
\hline
\end{tabular}


The distribution of tracer amounts of $\mathrm{T} 4-{ }^{181} \mathrm{I}$ between the thyroxine-binding proteins of fetal sera is illustrated in Fig. 3. The per cent of the T4- ${ }^{131} \mathrm{I}$ associated with TBG increased rapidly to $24 \mathrm{wk}$, maintaining a high degree of correlation with the crown-rump length $(r=0.887, P<0.001)$. By 24 wk greater than $83 \%$ of the tracer is bound to TBG. Between $24 \mathrm{wk}$ and term, however, only a minimal increase is noted despite tripling on the TBG capacity during this same period.

The per cent of the radioactive ligand bound to TBPA

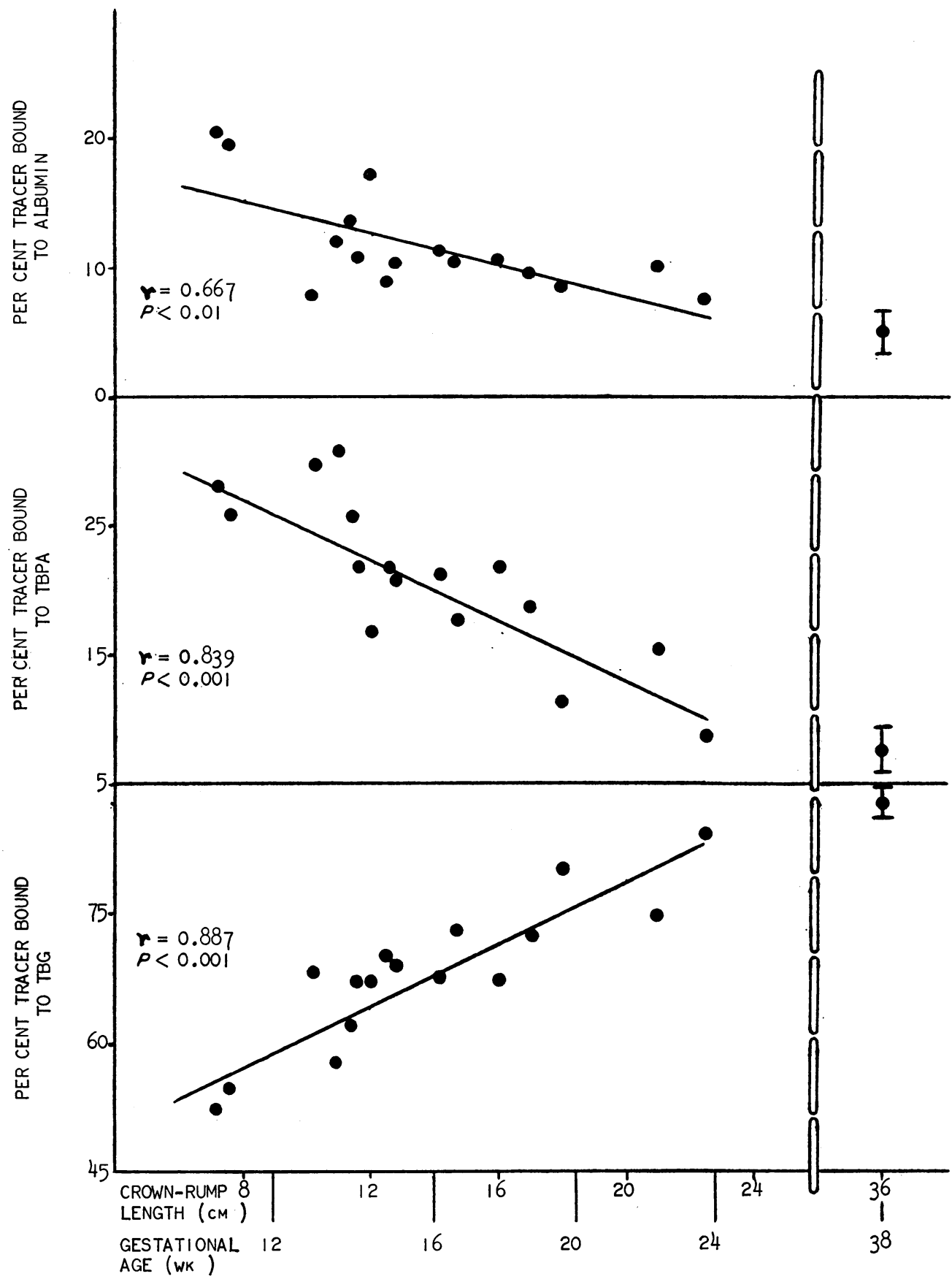

FIGURE 3 The distribution of tracer thyroxine $-{ }^{131} \mathrm{I}$ among the thyroxine-binding proteins. The linear correlation to crown-rump length is significant in each. By 24 wk gestation all are approaching term levels. 


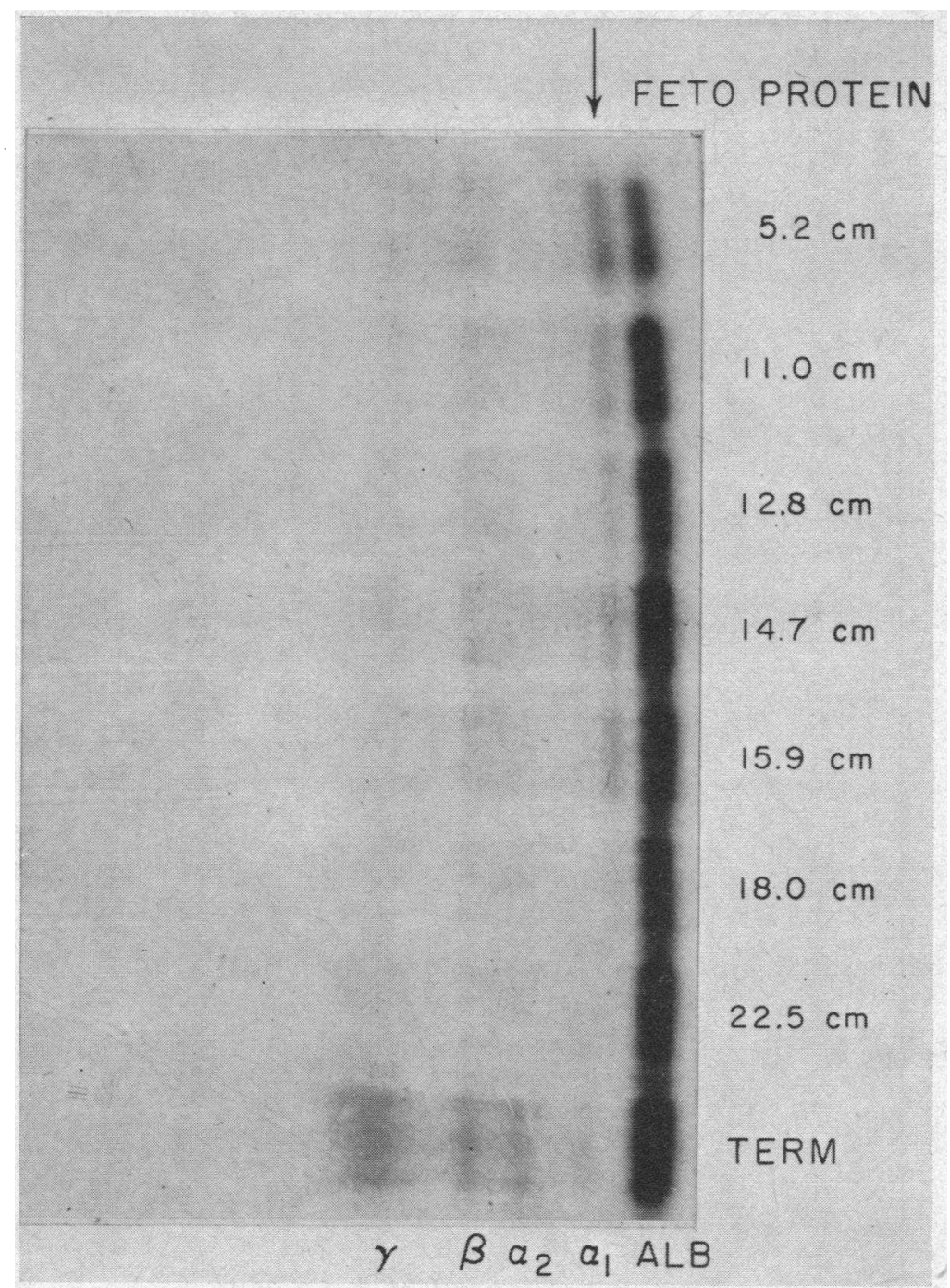

FigURE 4 Electrophoresis of fetal serum proteins on a cellulose acetate membrane and stained with Ponceau red. All the protein fractions are clearly seen in the term and older fetal specimens; however, the $\alpha_{1^{-}}$and $\gamma$-globulin were difficult to identify in younger fetuses. The $\alpha$ fetoprotein is seen in fetuses from 5.2 to $15.9 \mathrm{~cm}$ crown-rump length. It is most clearly distinguishable from the $\alpha_{1}$ globulin band in the $14.7 \mathrm{~cm}$ fetus.

and albumin decreased to term levels by 24 wk gestation. Each maintained a significant negative linear correlation to the crown-rump length.

A fetal protein, originally described by Bergstrand and Czar (13) as fetal $\times$ substance, with electrophoretic migration characteristically occurring between albumin and $\alpha_{1}$-globulin, was identified by microelectrophoresis on a cellulose acetate membrane (Fig. 4, Table II). It was detected in the largest concentration in the smallest fetus, $5.2 \mathrm{~cm}$ crown-rump length, and thereafter it decreased in concentration until it was no longer detectable in the $18 \mathrm{~cm}$ fetus. During this period, albumin increased in concentration.

Free thyroxine concentration (FT4) in 13 fetal sera correlated directly with the crown-rump length ( $r=$ $0.908, P<0.001)$. By $18-20$ wk gestation the FT4 was comparable with that observed in fetuses of 38 wk gestation (Fig. 5A). This contrasted with the total serum thyroxine concentration, which maintained a linear relation to gestational age but continued to increase until term (Fig. 1A). The free thyroxine fraction (FT4F) decreased linearly as related to crown-rump length (Fig. 5B). 
Radioimmunoassayable $\mathrm{TSH}$ was detected in the smallest fetus examined at 78 days gestation (Fig. 6). This sample, however, had a high TSH level compared with most of the fetuses in the 11-14 wk period of gestation. The remainder of the young fetuses have TSH levels of $4 \mu \mathrm{U} / \mathrm{cc}$ or less until 16-18 wk. Specimens older than 18 wk were within the range of term sera.

All but one of the fetal sera examined had values greater than the lower limit of sensitivity of the assay, $1.25 \mu \mathrm{U} / \mathrm{cc}$. These are high compared with $\mathrm{TSH}$ levels seen in children and adults, where about $40 \%$ of specimens are below assay sensitivity (11).

No correlation was demonstrated between the TSH and total thyroxine in fetal sera 11-24 wk gestation or at full term. The TSH and FT4 concentrations increased in a parallel manner, but TSH appeared to reach the term range slightly before the FT4. A linear

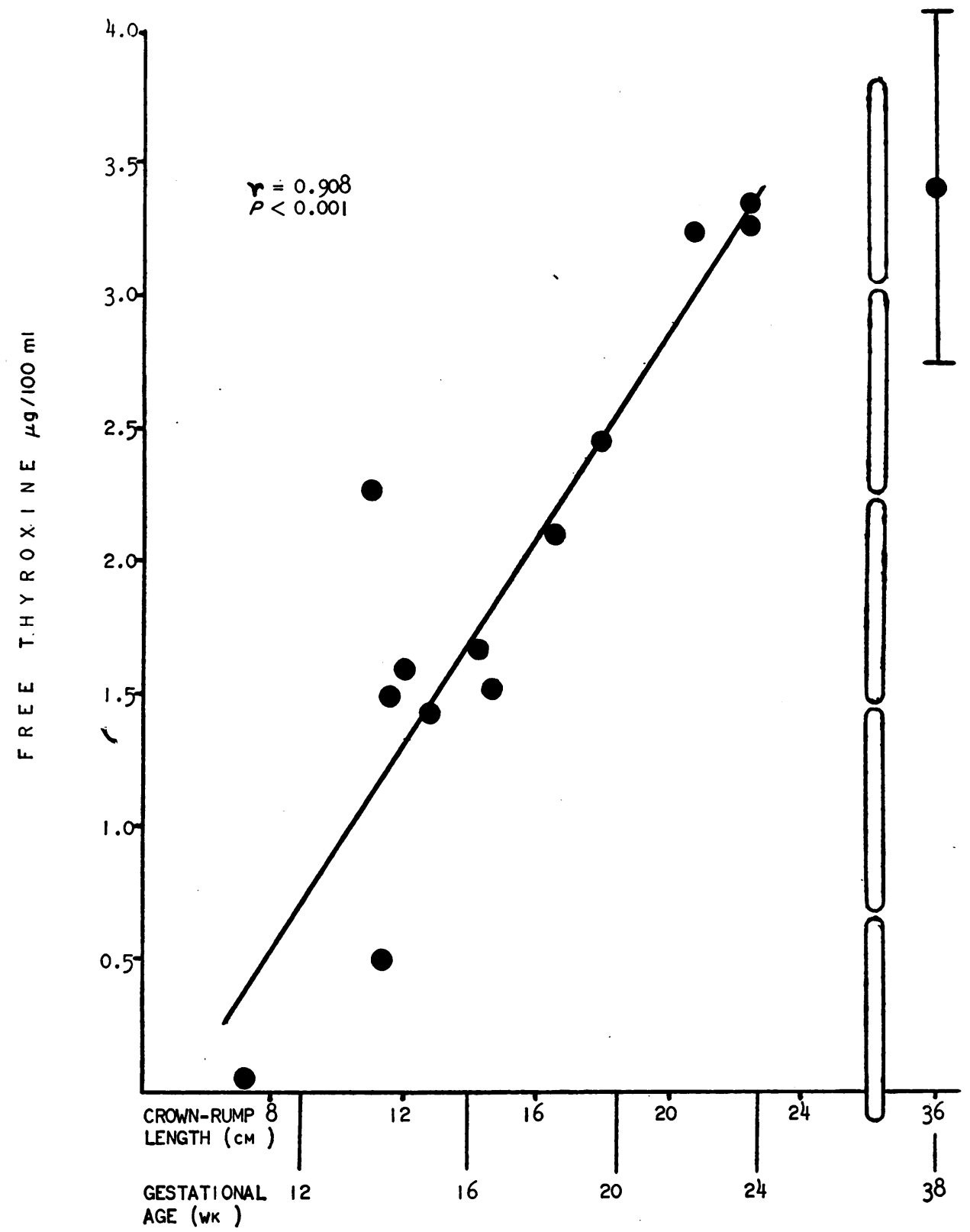

FIGURE 5 A Free thyroxine levels during the gestational period from 11 to 24 wk. Fetal levels reach within $1 \mathrm{SD}$ of the mean term level by 20 wk gestation. 


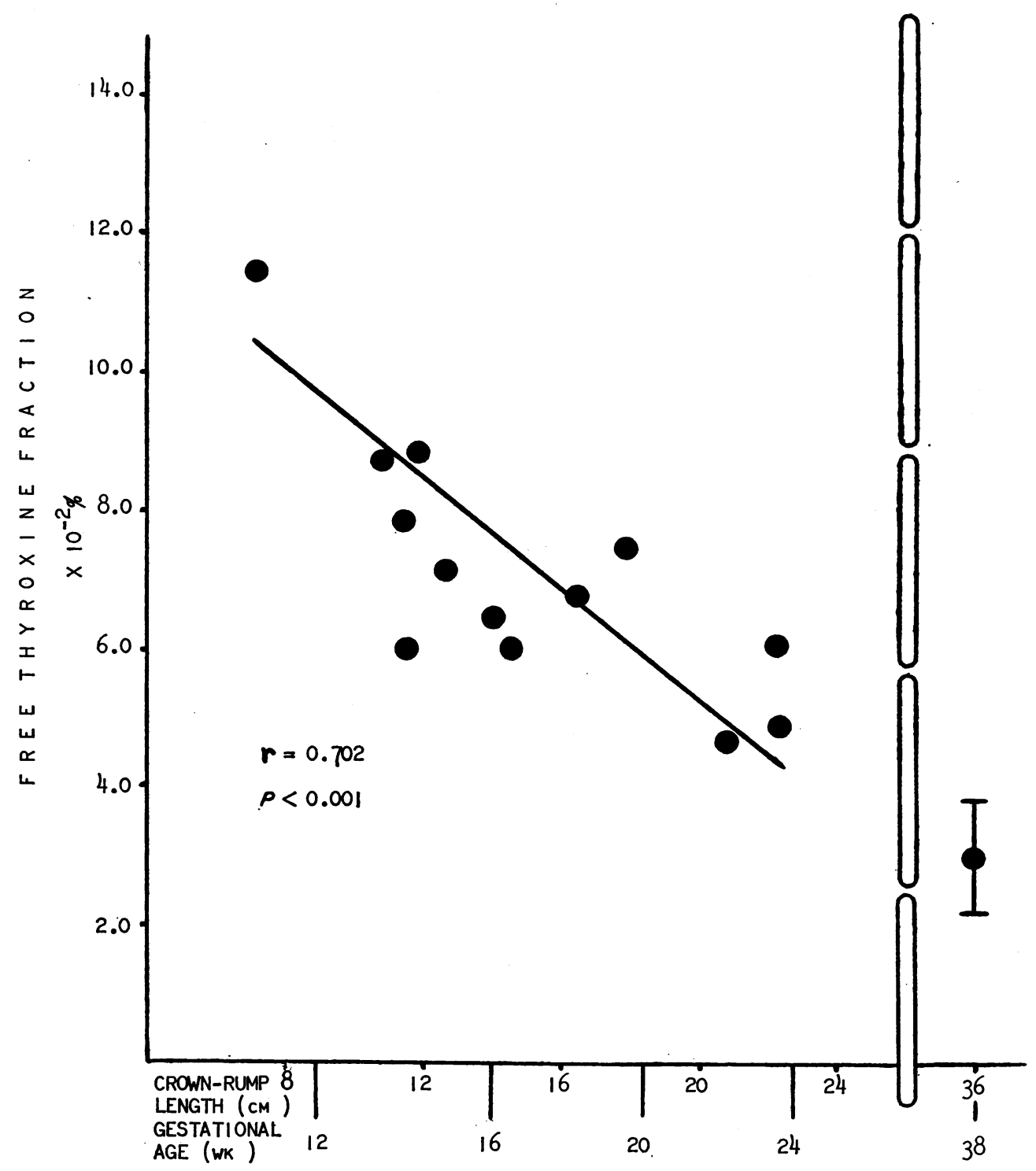

Figure $5 \mathrm{~B}$ The dialyzable fraction of thyroxine in fetuses from 11 to 24 wk gestation.

correlation was demonstrated between TSH and FT4 through the range of fetal specimens examined (Fig. 7).

FT4 concentrations were determined in five paired maternal and fetal sera and 16 paired maternal and term infant sera (Fig. 8). No difference was demonstrated between the maternal and term sera $(t=1.11, P>0.2)$. However, significantly higher maternal levels were noted earlier in fetal life, and this difference decreased with advancing gestation.

The TSH levels determined on similary paired sera indicated a significant difference between maternal and term sera by a paired $t$ test $(t=5.90, P<0.01$; Fig. 9$)$. Correspondingly higher fetal TSH levels were found for most of the gestational period except for the two fetuses in the 11-13 wk range. The high TSH value noted in the youngest fetus of the series was associated with an elevated maternal value. This is the only maternal TSH that was observed to exceed that of the paired fetus or newborn.

\section{DISCUSSION}

The histological and functional differentiation of the thyroid and pituitary glands in the human fetus is summarized in Fig. 10. The cytologic differentiation of the pituitary begins at about 8 wk gestation (3), and the first P.A.S. positive basophils appear at about $9 \mathrm{wk}$ 
gestation (4). Histochemical evidence of thyrotroph formation, however, does not occur until 13 wk (4). TSH was detected in significant concentration in the serum of a fetus of 78 days gestation in the present study. It is quite possible, thowever, that TSH could have been detected earlier if younger fetuses were studied. Only one fetus, of 11.8 wk gestation, had a TSH level below the sensitivity of the assay method. The appearance of immunoassayable TSH in fetal serum, then, correlates with the appearance of the

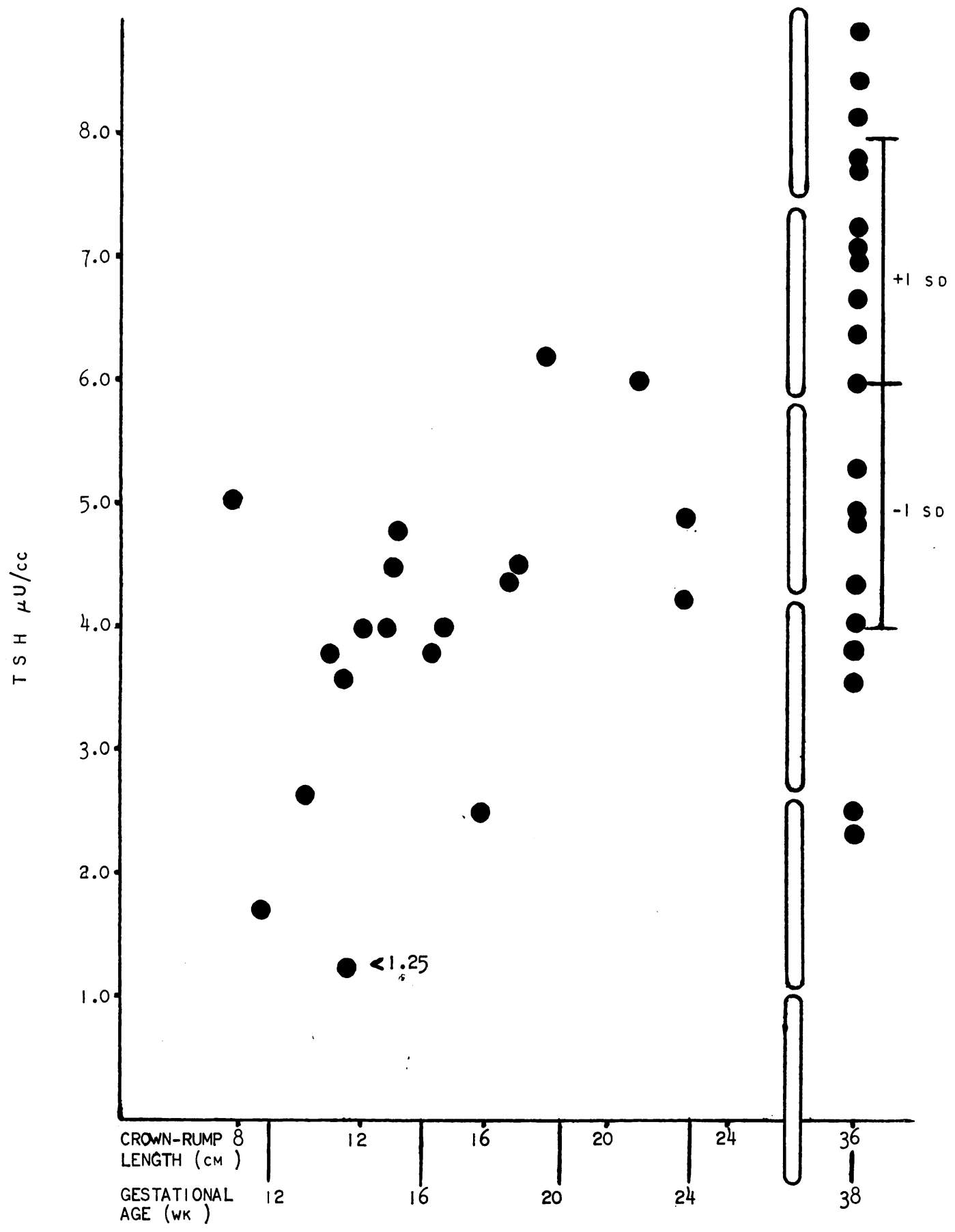

FIgURE 6 Radioimmunoassayable TSH in fetuses from 11 to 24 wk gestation compared with 20 term sera. Fetal sera are nearly all within 1 sD of the mean term level by 16 wk gestation. 


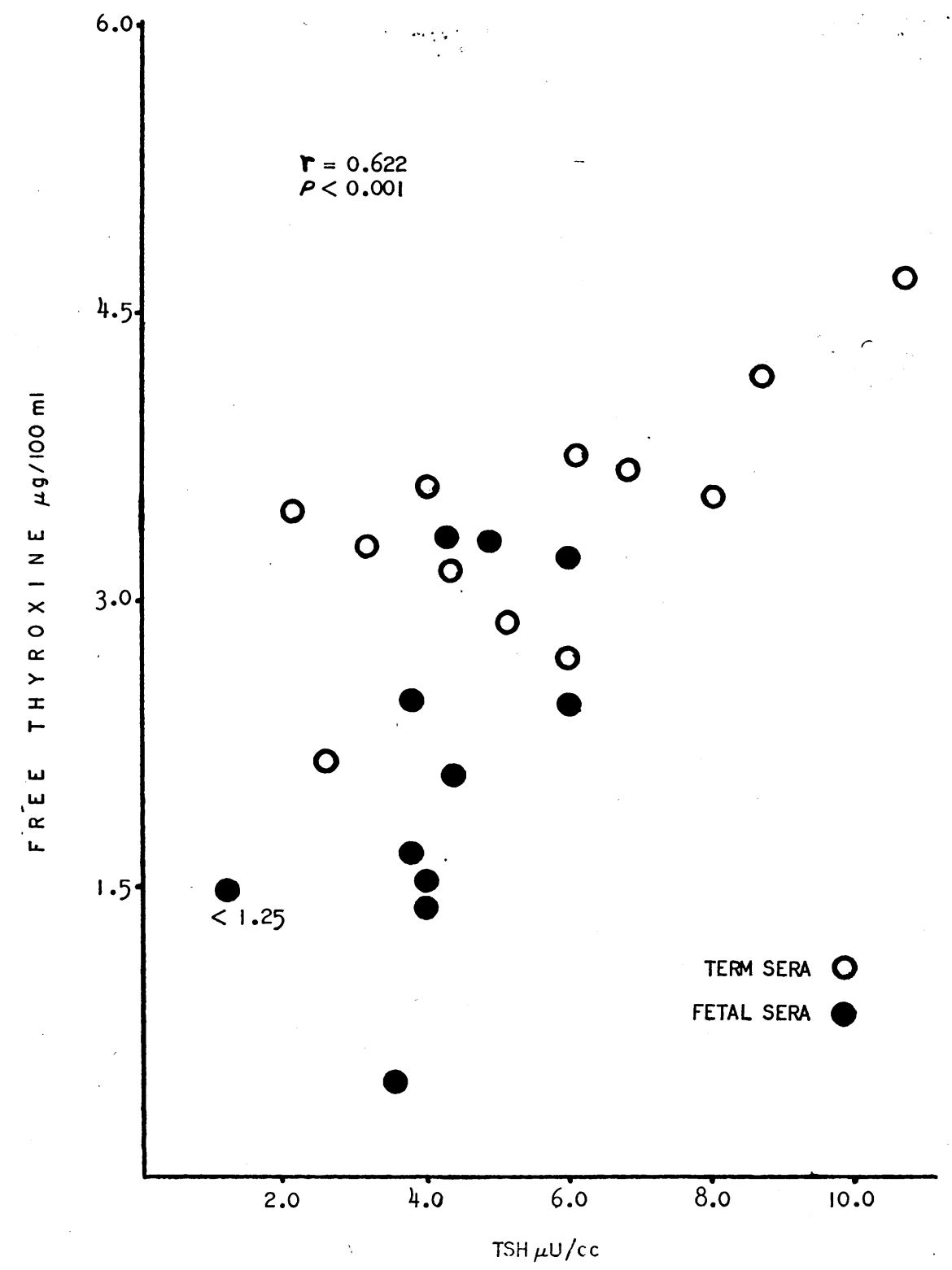

FIGURE 7 Free thyroxine-TSH correlation in fetal and term sera. A highly significant linear correlation is demonstrated.

P.A.S. positive basophil, or possibly with even earlier differentiation of the pituitary. Bioassayable hormone has been detected as early as $12 \mathrm{wk}$ in fetal pituitary extracts (14), and Gitlin and Biasucci (5) have recently reported that fetal pituitaries are capable of incorporating amino acids ${ }^{14} \mathrm{C}$ into $\mathrm{TSH}$ in cell culture at $14 \mathrm{wk}$ gestation.

The fetal thyroid gland is capable of organically binding iodine and forming iodothyronines by $10 \mathrm{wk}$ gestation (2). This corresponds to the period of differentiation in which intracellular canaliculi have undergone extracellular fusion, and colloid formation is first noted $(1,2)$. It is, however, at least $6 \mathrm{wk}$ after thyroglobulin synthesis is detected (15).

In the present study thyroxine was identified in serum at 78 days but not at 74 days gestation, indicating that it appears about $1 \mathrm{wk}$ after the initiation of intrathyroidal synthesis. It is possible, however, that with more concentrated serum extracts in the younger fetuses, thyroxine could be identified earlier. Protein-bound iodine has been detected in fetal sera as early as $13 \mathrm{wk}$ gestation (16). 


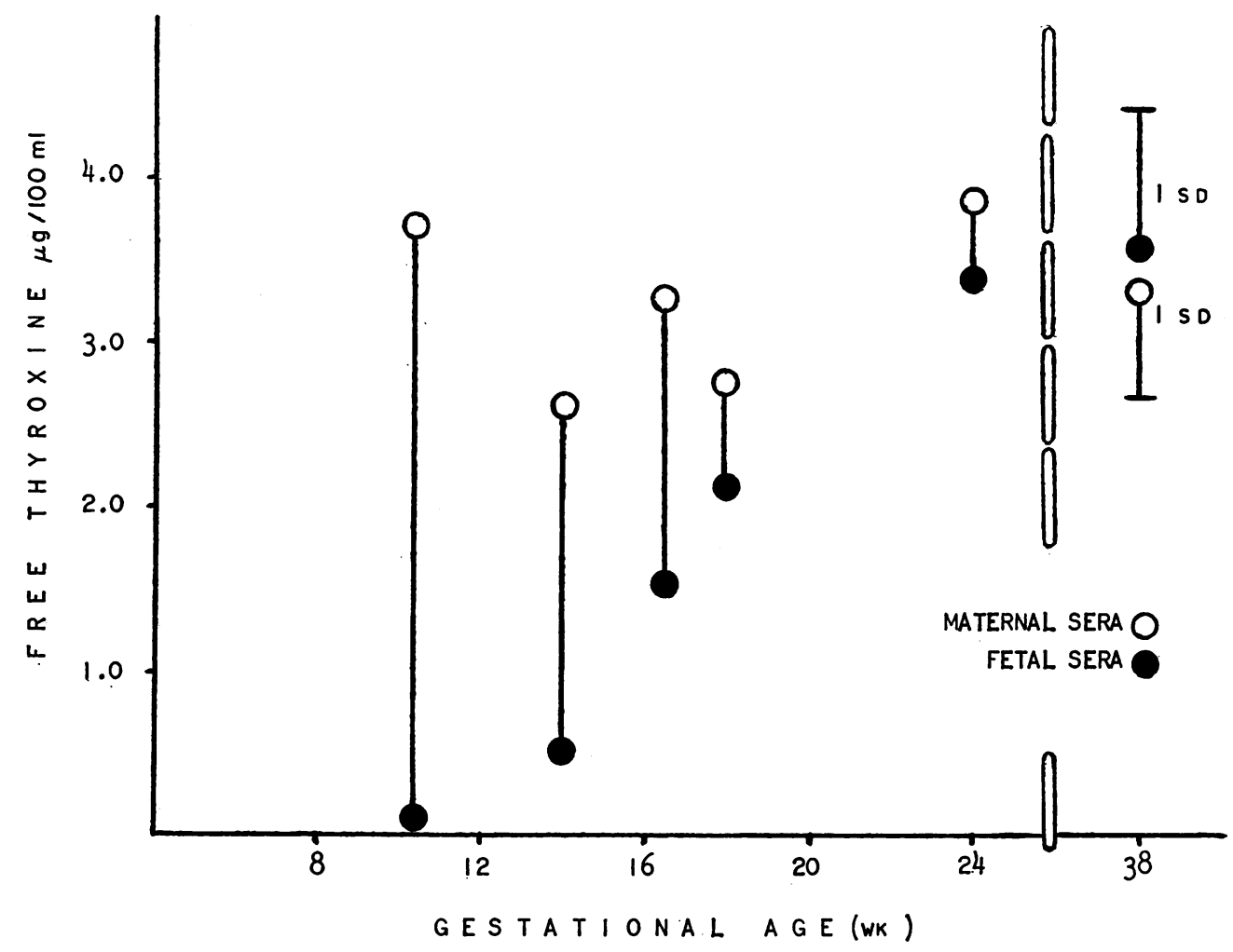

FIGURE 8 Free thyroxine in paired maternal-fetal sera. A large maternal to fetal gradient is noted in young fetal specimens, decreasing with advancing gestation. No difference was detected between paired maternal and term infant sera.

Thyroxine-binding globulin and thyroxine-binding prealbumin have been identified as early as 74 days estimated gestational age (16). Specimens from younger fetuses have not been examined for these thyroxinebinding proteins. Albumin in significant quantity was detected in a fetus of 64 days estimated gestational age in the present study. The fetal postalbumin, $\alpha$-fetoprotein, was detected in largest quantity in the youngest fetus studied. Its role as a thyroxine-binding protein, however, has not been well studied.

It was observed that TBG binding, measured as the percentage of tracer amounts of $\mathrm{T} 4{ }^{-181} \mathrm{I}$ associated with TBG, is much greater than that seen in adults or children. At 20 wk gestation, with TBG capacity of $7.7 \mu \mathrm{g} / 100 \mathrm{ml}$, fetal TBG is able to bind $78 \%$ of tracer T4- ${ }^{181} \mathrm{I}$. Adult sera with much higher TBG capacity (males $15.6 \pm 2.9$ (sD) $\mu \mathrm{g} / 100 \mathrm{ml}$; females $18.0 \pm 2.9$ (sD) $\mu \mathrm{g} / 100 \mathrm{ml}$ ) bind slightly less tracer (males 70.9 \pm 4.7 (SD) \%; females $76.9 \pm 4.1$ (SD) \%).

In an attempt to distinguish the effects of relatively low concentrations of albumin and TBPA on the distribution of tracer, and the possibility that fetal TBG has unusual thyroxine-binding characteristics, a theoretical association constant for TBG was calculated.
Using the Robbins and Rall formulation (17) an association constant of $5.3 \times 10^{10}$ was estimated for fetuses of $20 \mathrm{wk}$ gestation. The presence of the $\alpha$-fetoprotein does not allow calculation of the constant before this time. This fetal association constant compares with estimated values of $5.1 \times 10^{10}$ in newborns, $5.0 \times 10^{10}$ in adult males, and $4.6 \times 10^{10}$ in adult females. Robbins and Rall (17) estimate the TBG association constant at $4 \times 10^{10}$. These calculations must assume that fetal and newborn serum albumin have the same molecular weight and the same binding characteristics as adult serum albumin. Accepting these assumptions, then, fetal TBG has a normal association constant, and the binding characteristics described with tracer amounts of $\mathrm{T} 4{ }^{-181} \mathrm{I}$ are probably the result of relatively low concentrations of serum TBPA and albumin.

Serum thyroxine, FT4, and TSH levels increased during the gestational period 11-24 wk. Serum thyroxine continued to rise until term coincident with a similar rise in TBG levels, while TSH reached term levels by $16 \mathrm{wk}$ and FT4 by $20 \mathrm{wk}$ gestation. TSH was shown to correlate directly with the rise in FT4 levels but not thyroxine levels. The parallel changes and direct correlation of FT4 and TSH likely indicate that TSH 
secretion in the fetus is responsive to FT4 levels from very early in gestation, possibly as early as $11 \mathrm{wk}$. It seems unlikely that the parallel changes represent independent maturation and autonomous secretion of hormones of the thyroid and pituitary glands. In addition, the rise in FT4 levels, which occurs in the face of a simultaneous increase in TBG, would indicate that TSH stimulation of thyroxine secretion is responding as if it were being stimulated by suboptimal levels of circulating thyroxine. The attempt to demonstrate that thyroxine secretion and the rise in serum thyroxine levels were occurring at a more rapid rate than increases in TBG concentration was not possible (Fig. 2). However, the observed increase in FT4 levels allows an assumption of this relationship.

Fetal TSH levels after 16 wk gestation are high compared with normal children or adults. Why TSH is maintained at high levels during most of fetal life is difficult to explain. It is unlikely that this represents cross-reactivity with human chorionic gonadotropin (HCG) or human chorionic thyrotropin (HCT). Excess HCG is added to the antiserum to saturate reactive binding sites (18), and HCT has been demonstrated to react very poorly with the NIAMD HTSH antiserum $(19,20)$. It is also unlikely that maternal TSH is able to cross the placenta to enter the fetal circulation and contribute to fetal TSH levels. The relative difference in TSH levels in maternal and fetal sera (Fig. 9) and the observations in animals (21) support this concept.

Assuming, then, that the levels represent pituitary TSH of fetal origin, one must postulate either a persistent stimulus to TSH release in utero or a hypothalamic-pituitary mechanism which is not suppressible by free thyroxine levels in the normal range for children. There are no data available to confirm either of these hypotheses.

No correlation was demonstrated between maternal TSH levels and any of the parameters of fetal thyroid function. This probably reflects the inability of maternal TSH to cross the placenta. A more important question, however, is whether free thyroxine crosses the placenta in quantities sufficient to affect the developing fetus. At term both L-thyroxine $(22,23)$ and triiodothyronine $(24,25)$ are capable of crossing the human placenta, but with some difficulty. It has been estimated in primates that only $0.01 \%$ of the total thyroxine utilized by the fetus late in pregnancy is of maternal origin (26). In the present study a large maternal to fetal gradient of free thyroxine was found during early fetal life, and this decreased with advancing gestation. This would suggest that some contribution of maternal thyroxine is possible in the young fetus. Even if occurring, this

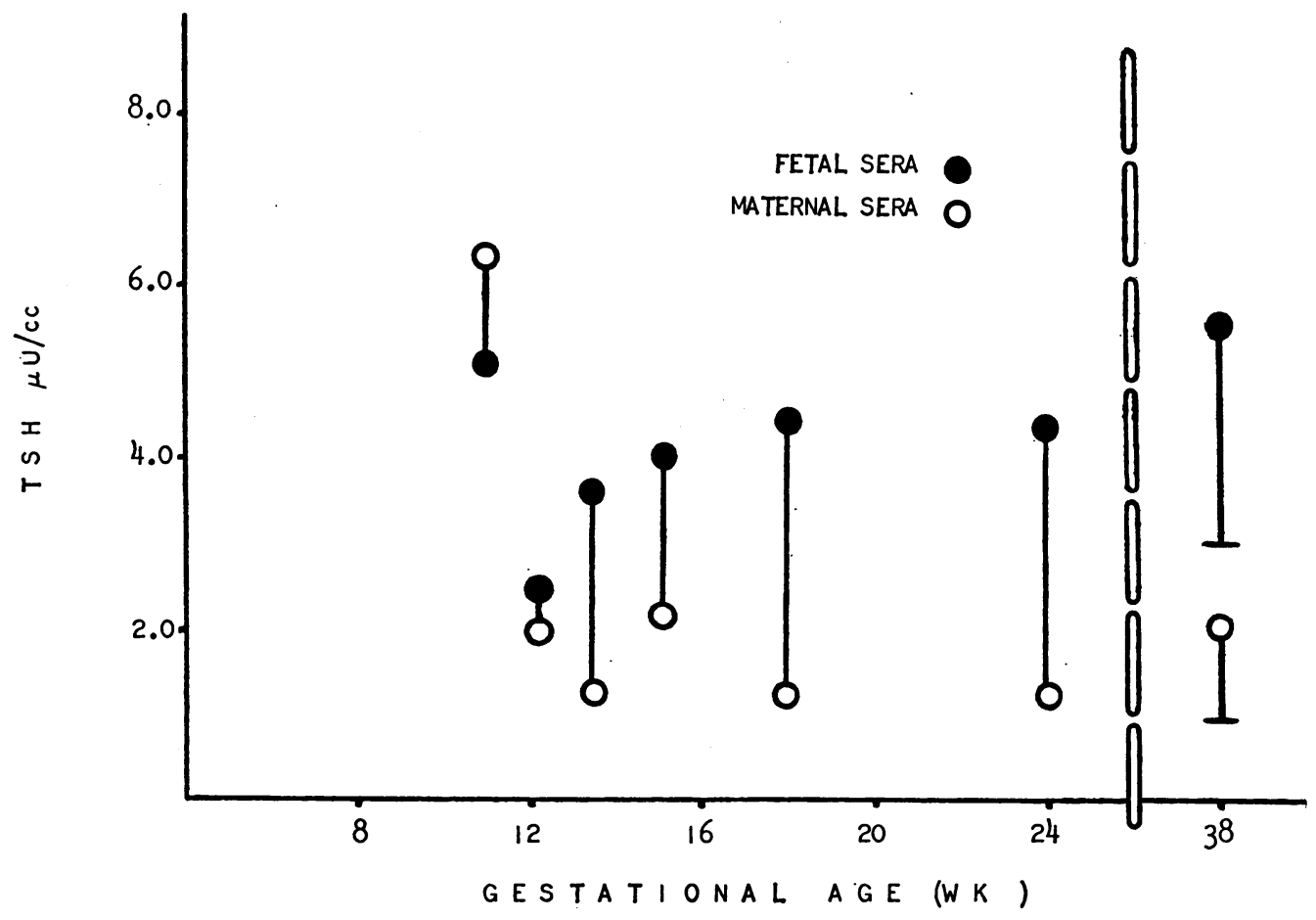

FIGURE 9 Radioimmunoassayable TSH in paired maternal-fetal sera. TSH levels are significantly higher at term and in fetal specimens more than 14 wk gestation. Differences are not as pronounced before this period. 


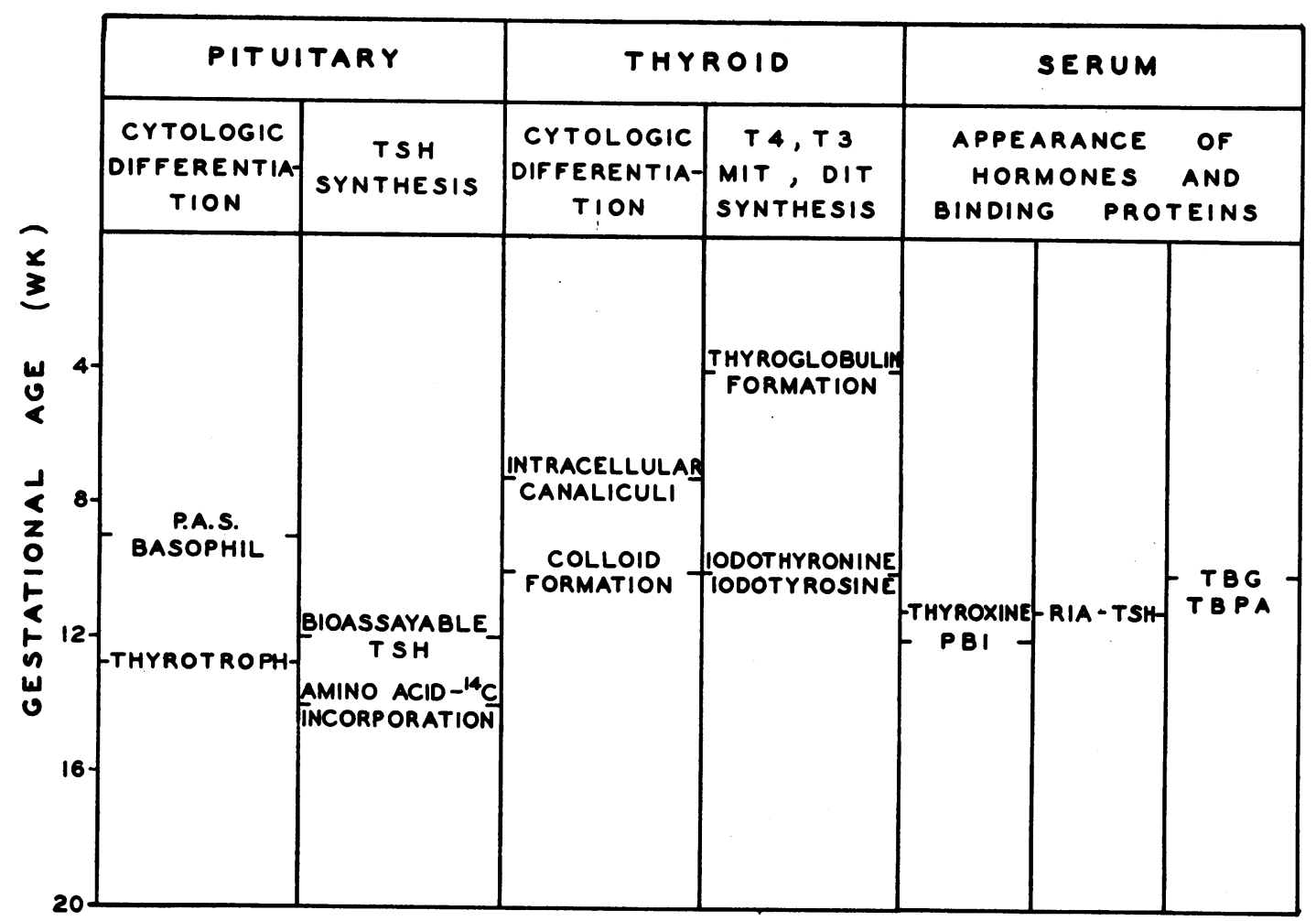

FIGURE 10 The histological and functional differentiation of the human thyroid and pituitary gland relating to the appearance of $\mathrm{TSH}$, and thyroxine and its binding proteins, in the serum.

contribution would certainly decrease later in fetal development, as fetal free-thyroxine concentration approaches term levels. It is also manifest that in the absence of evidence for a thyroxine pump, a significant block to the transplacental movement of thyroid hormone must be postulated even in early fetal life.

One question that remains unanswered is whether the small amounts of thyroxine which are able to cross the placenta during early gestation are necessary for fetal maturation. Animal evidence would suggest that neither fetal nor maternal thyroxine is necessary for most fetal growth. Hamburgh, Lynn, and Weiss (27) showed that propylthiouracil-fed fetal rats have normal skeletal and cerebral maturation at birth and retain normal puzzlesolving skills if thyroxine replacement was begun immediately after delivery. This is not the experience in humans, as early thyroxine replacement in cretins is still associated with a significant degree of retardation in some (28). This finding, however, may be the result of a deficiency of thyroid hormone during the late stages of fetal development when fetal thyroid function is at optimal levels. The role of maternal thyroxine, if any, remains unknown in very early fetal development.

\section{ACKNOWLEDGMENTS}

The authors wish to acknowledge the technical assistance of Mrs. Janice Owings and the secretarial assistance of Mrs. Mary Westervelt.

This work was supported by Research Grant HD-01852 and GM-10548 of the U. S. Public Health Service. Dr. Greenberg is a Research Fellow supported by the Medical Research Council of Canada. Dr. Czernichow is a Research Fellow supported by the Ministere des Affaires Etrangeres Direction Generale des Relations Culturelles of France. Dr. Blizzard is the Eudowood Professor of Pediatrics at The Johns Hopkins University School of Medicine.

\section{REFERENCES}

1. Shepard, T. H. 1968. Development of the human fetal thyroid. Gen. Comp. Endocrinol. 10: 174.

2. Shepard, T. H. 1967. Onset of function in the human fetal thyroid: biochemical and radioautographic studies from organ culture. J. Clin. Endocrinol. Metab. 27: 945.

3. Pearse, A. G. E. 1952. The cytochemistry and cytology of the normal anterior hypophysis investigated by the trichrome-periodic and acid-Schiff method. J. Pathol. Bacteriol. 64: 811.

4. Rosen, F., and C. Ezrin. 1966. Embryology of the thyrotroph. J. Clin. Endocrinol. Metab. 26: 1343.

5. Gitlin, D., and A. Biasucci. 1969. Ontogenesis of immunoreactive growth hormone, follicle-stimulating hor- 
mone, thyroid-stimulating hormone, luteinizing hormone, chorionic prolactin and chorionic gonadotropin in the human conceptus. J. Clin. Endocrinol. Metab. 29: 926.

6. Murphy, B. P., and C. Jachan. 1965. The determination of thyroxine by competitive protein-binding analysis employing an anion-exchange resin and radiothyroxine. J. Lab. Clin. Med. 66: 161.

7. Inada, M., and K. Sterling. 1967. Thyroxine transport in thyrotoxicosis and hypothyroidism. J. Clin. Invest. 46: 1442 .

8. Sterling, K., and M. A. Brenner. 1966. Free thyroxine in human serum: simplified measurement with the aid of magnesium precipitation. J. Clin. Invest. 45: 153.

9. Favino, A., D. Emrich, and A. von zur Muhlen. 1967. Separation and quantitative determination of ${ }^{131}$ I-triiodothyronine and ${ }^{131} \mathrm{I}$-thyroxine in human plasma by thin layer chromatograph. Acta Endocrinol. 54: 362.

10. Schussler, G. C., and J. E. Plager. 1967. Effect of preliminary purification of ${ }^{131}$ I-thyroxine on the determination of free thyroxine in serum. J. Clin. Endocrinol. Metab. $27: 242$.

11. Greenberg, A. H., P. Czernichow, W. Hung, W. Shelley, T. Winship, and R. M. Blizzard. 1970. Juvenile chronic lymphocytic thyroiditis: clinical, laboratory and histological correlations. J. Clin. Endocrinol. Metab. 30: 293.

12. Streeter, G. L. 1920. Weight, sitting height, head size, foot length and menstrual age of human embryo. Contributions to Embryology by the Carnegie Institute of Washington. 11: 143 .

13. Bergstrand, C. G., and B. Czar. 1957. Paper electrophoretic study of human fetal serum proteins with demonstration of a new protein fraction. Scand. J. Clin. Lab. Invest. 9: 277

14. Costa, A., F. Cottino, M. Dellepiane, G. M. Ferraris, L. Lenart, C. Magro, G. Patrito, and G. Zoppetti. 1965. Thyroid function and thyrotropin activity in mother and fetus. In Current Topics in Thyroid Research. C. Cassano and M. Andreoli, editors. Academic Press Inc., New York. 738.

15. Gitlin, D., and A. Biasucci. 1969. Ontogenesis of immunoreactive thyroglobulin in the human conceptus. J. Clin. Endocrinol. Metab. 29: 849.
16. Andreoli, M., and J. Robbins. 1962. Serum proteins and thyroxine-protein interaction in early human fetuses. J. Clin. Invest. $41: 1070$.

17. Robbins, J., and J. E. Rall. 1967. The iodine-containing hormones. In Hormones in Blood. C. H. Gray and A. L. Bacharach, editors. Academic Press Inc., New York. 2nd edition. 1: 383.

18. Odell, W. D., L. Vanslager, and R. Bates, 1968. Radioimmunoassay of human thyrotropin. U. S. A. E. C. Symp. Ser. 13: 185.

19. Fisher, D. A., W. D. Odell, C. J. Hobel, and R. Garza. 1969. Thyroid function in the term fetus. Pediatrics. 44: 526.

20. Hennen, G., J. G. Pierce, and D. Freychet. 1969. Human chorionic thyrotropin: further characterization and study of its secretion during pregnancy. J. Clin. Endocrinol. Metab. 29: 581.

21. Peterson, R. R., and W. C. Young. 1952. The problem of placental permeability for thyrotrophin, propylthiouracil and thyroxine in the guinea pig. Endocrinology. 50: 218.

22. Grumbach, M. M., and S. C. Werner. 1956. Transfer of thyroid hormone across the human placenta at term. J. Clin. Endocrinol. Metab. 16: 1392.

23. Fisher, D. A., H. Lehman, and C. Lackey. 1964. Placental transport of thyroxine. J. Clin. Endocrinol. Metab. 24: 393.

24. Dussault, J., V. V. Row, G. Lickrish, and R. Volpe. 1969. Studies of serum triiodothyronine concentration in maternal and cord blood: transfer of triiodothyronine across the placenta. J. Clin. Endocrinol. Metab. 29: 595.

25. Raiti, S., G. B. Holzman, R. L. Scott, and R. M. Blizzard. 1967. Evidence for the placental transfer of triiodothyronine in human beings. N. Engl. J. Med. 277: 456.

26. Kock, H. C., W. Reichert, L. Stolte, H. van Kessel, and J. Seelen. 1965. Placental thyroxine transfer and foetal thyroxine utilisation. Acta Physiol. Pharmacol. Neer. 13: 363.

27. Hamburgh, M., E. Lynn, and E. P. Weiss. 1964. Analysis of the influence of thyroid hormone on prenatal and postnatal maturation of the rat. Anat. Rec. 150: 147.

28. Smith, D. W., R. M. Blizzard, and L. Wilkins. 1957. The mental prognosis in hypothyroidism of infancy and childhood. Pediatrics. 19: 1011. 